\title{
Lipolytic activity of Staphylococcus aureus from human wounds, animals, foods, and food-contact surfaces in Brazil
}

\author{
Jessica Bezerra dos Santos Rodrigues ${ }^{1}$, Taiz Siqueira Pinto ${ }^{1}$, Cybelle Pereira de Oliveira ${ }^{1}$, Francisca \\ Inês de Sousa Freitas ${ }^{2}$, Maria do Socorro Vieira Pereira ${ }^{1}$, Evandro Leite de Souza ${ }^{3^{*}}$, José Pinto de \\ Siqueira-Júnior ${ }^{1}$ \\ ${ }^{1}$ Laboratório de Genética de Microrganismos, Departamento de Biologia Molecular, Universidade Federal da \\ Paraíba, João Pessoa, Paraíba, Brasil \\ ${ }^{2}$ Laboratório de Parasitologia, Departamento de Ciências Farmacêuticas, Universidade Federal da Paraíba, João \\ Pessoa, Paraíba, Brasil \\ ${ }^{3}$ Laboratório de Microbiologia de Alimentos, Departamento de Nutrição, Universidade Federal da Paraíba, João \\ Pessoa, Paraíba, Brasil
}

\begin{abstract}
Introduction: $S$. aureus is of great importance to public health due to its pathogenicity. This study aimed to evaluate lipase production by $S$. aureus isolates from different sources.

Methodology: Lipolytic activity was determined using Tween-Calcium agar ( 48 hours; $35^{\circ} \mathrm{C}$ ).

Results: Eighty-six percent of the isolates from human wounds were positive for lipase production. The frequencies of isolates positive for lipase production were $33.3 \%$ from cow udders, $15.4 \%$ from the nasal cavities of cattle, $82.9 \%$ from ricotta cheeses, and $100 \%$ and $91.7 \%$ from meat- and vegetable-contact surfaces, respectively.

Conclusion: The production of lipase varied among the isolates according to their source.
\end{abstract}

Key words: Staphylococcus; phenotypic characterization; lipolytic activity; virulence.

J Infect Dev Ctries 2014; 8(8):1055-1058. doi:10.3855/jidc.3697

(Received 18 April 2013 - Accepted 19 April 2014)

Copyright (C) 2014 Rodrigues et al. This is an open-access article distributed under the Creative Commons Attribution License, which permits unrestricted use, distribution, and reproduction in any medium, provided the original work is properly cited.

\section{Introduction}

Staphylococcus aureus is widespread in nature and is the most frequent bacteria found in skin infections, although it is able to colonize nearly all human tissues [1]. In the nosocomial environment, skin infections caused by $S$. aureus are commonly found during the post-surgical phase; in the general community, these infections are frequently observed as abscesses, impetigo, folliculitis, boils, and necrotizing fasciitis [2].

$S$. aureus has been recognized worldwide as the etiological agent of most cases of foodborne disease, thereby making it of great interest in the field of the microbiological safety of foods $[3,4]$. The pathogenesis of infections caused by $S$. aureus depends on the production of surface proteins involved in bacterial adhesion to host tissues and of extracellular proteins such as catalase, thermonuclease, coagulase, and lipase [5]. S. aureus is known as a potential lipase-producing, opportunistic pathogenic bacterium that is able to interfere with the immune host defense by eliminating granulocyte chemotaxis and reducing phagocytosis [5-7].

In addition to its role in the pathogenicity of $S$. aureus, the influence of lipase on food quality as a result of its ability to hydrolyze lipid components in foods is a concern. Microorganisms with lipolytic activity can increase the rate of food deterioration through their action on lipids and as a result of the accumulation of intermediate- and end-products that change the flavor of foods $[4,8]$.

This study compared lipase production by Brazilian strains of $S$. aureus isolated from animals, human wounds, foods, and food-contact surfaces.

\section{Methodology}

The S. aureus isolates were obtained from infected human wounds in a college public hospital in the city of João Pessoa, Paraíba, Brazil (50 isolates); from cattle (udder: 30 isolates; nasal cavities: 13 isolates) 
from a small farm in the city of Patos, Paraíba, Brazil; from bovine ricotta cheeses of different brands that were marketed in local supermarkets in the city of João Pessoa, Paraíba, Brazil (41 isolates); and from meat-contact surfaces (24 isolates) and vegetablecontact surfaces (24 isolates) in food service facilities of a public hospital in the city of João Pessoa, Paraíba, Brazil.

$S$. aureus was isolated as described elsewhere $[9,10]$. The samples (swabs of samples from wounds, animals, and food-contact surfaces; $25 \mathrm{~g}$ of cheeses) were first selectively enriched in brain-heart infusion broth $(225 \mathrm{~mL})$ supplemented with $\mathrm{NaCl}(75 \mathrm{~g} / 1000$ $\mathrm{mL}$ ) for 24 hours. Then, tenfold serial dilutions of the cultures were prepared $\left(10^{-1}-10^{-4}\right)$ in sterile peptone water $(10 \mathrm{~g} / 1000 \mathrm{~mL})$, and $100-\mu \mathrm{L}$ aliquots were plated on salt mannitol agar (for samples from wounds and animals) or Baird-Parker agar (for samples from food-contact surfaces and cheeses), both supplemented with potassium tellurite $(10 \mathrm{~g} / 1000 \mathrm{~mL})$ and egg yolk emulsion $(50 \mathrm{~mL} / 1000 \mathrm{~mL})$, at $35^{\circ} \mathrm{C}$. Typical colonies were selected and placed on nutrient agar slants. The isolated strains were then identified using biochemical tests (Gram stain, catalase activity, coagulase reaction, thermonuclease production, and mannitol and glucose fermentation). The strains that were confirmed as $S$. aureus were refrigerated $\left(7^{\circ} \mathrm{C}\right)$ in nutrient agar slant tubes.

The lipolytic activity of the isolates was determined according to Sierra (1957) [11]. The isolates were first cultivated in brain-heart infusion broth for 24 hours at $35^{\circ} \mathrm{C}$. Next, an aliquot $(100 \mu \mathrm{L})$ of the culture was grown on sterile plates containing Tween-Calcium agar $(10 \mathrm{~g} / 1000 \mathrm{~mL}$ peptone, 5 $\mathrm{g} / 1000 \mathrm{~mL}$ sodium chloride, $0.1 \mathrm{~g} / 1000 \mathrm{~mL}$ calcium chloride, $15 \mathrm{~g} / 1000 \mathrm{~mL}$ agar, and $10 \mathrm{~mL} / 1000 \mathrm{~mL}$ Tween 80 ) for 48 hours at $35^{\circ} \mathrm{C}$. Afterwards, lipaseproducing strains were identified by the presence of a halo of calcium soap crystals around their colonies that resulted from the action of lipase on Tween 80 (oleic acid ester). The experiments were carried out in triplicate on three different occasions and showed consistent results.

\section{Results}

A total of 182 isolates of $S$. aureus from different sources were tested for lipase production. From the isolates obtained from human wounds, 43/50 (86\%) produced lipase. In the isolates from animals, the highest frequency $(53.3 \% ; 16 / 30)$ of lipolytic activity was found in isolates from udders, while few isolates from nostrils showed lipolytic activity $(15.4 \% ; 2 / 13)$. Of the isolates obtained from cheeses, $82.9 \%(34 / 41)$ produced lipase. All isolates from meat-contact surfaces and $91.7 \%(22 / 24)$ of the isolates from vegetable-contact surfaces produced lipase. Of the total number of isolates that were tested, $77.5 \%$ $(141 / 182)$ were positive for lipase production (Table 1). Repeating the experiments showed consistent results.

\section{Discussion}

The higher frequency of positive lipase production $(86 \%)$ among the $S$. aureus isolates from human wounds (nosocomial environment) may be related to the neeed in these isolates of the lipolytic ability for colonization and establishment of the infectious process in human tissue. Early studies reported on the influence of lipases on abscess formation in rats and on the greater severity of infections caused by lipaseproducing $S$. aureus strains [12]. In the same study, higher counts of $S$. aureus $\left(10^{4}-10^{7} \mathrm{CFU} / \mathrm{g}\right)$ in the kidneys, livers, and spleens of rats were found in infections from positive lipase strains, which indicates the importance of this enzyme for the formation of abscesses and the invasion of organs.

Some researchers have reported that most $S$. aureus isolates obtained from cattle are not able to produce lipase, as opposed to isolates from humans, which show the ability to produce lipase $[13,14]$. A study carried out in Brazil found that most $S$. aureus cattle isolates were negative for lipase production and

Table 1. Lipase activity of isolates of S. aureus from different sources in Brazil

\begin{tabular}{lccc}
\hline \multirow{2}{*}{ Source } & Number of isolates & \multicolumn{2}{c}{ Isolates with lipolytic positive activity } \\
\cline { 3 - 4 } & & $\mathbf{N}^{\mathbf{0}}$ & $\mathbf{\%}$ \\
\hline Human wounds (hospital) & 50 & 43 & 86 \\
Animals (udder) & 30 & 16 & 53.3 \\
Animals (nostrils) & 13 & 2 & 15.4 \\
Cheese (ricotta) & 41 & 34 & 82.9 \\
Meat-contact surfaces & 24 & 24 & 100 \\
Vegetables-contact surfaces & 24 & 22 & 91.7 \\
Total & $\mathbf{1 8 2}$ & $\mathbf{1 4 1}$ & $\mathbf{7 7 . 5}$ \\
\hline
\end{tabular}


that most of the lipase producers were obtained from udders, which comes into contact with the handler during milking. This contact could increase the possibility of human contamination of the udder with lipase-producing S. aureus [15]. Of the isolates that were obtained from cow udders in this study, 53\% were positive for lipase production. Our findings confirm other studies that demonstrated the lack of lipase production among isolates of $S$. aureus from cattle.

Most S. aureus isolated from foods (ricotta cheese) and from meat- and vegetable-contact surfaces (food processing environments) were positive for lipase production. A low frequency of lipase production among isolates of $S$. aureus from chicken samples $(22.8 \%)$ [8] and an absence of lipase production among isolates of Staphylococcus spp. from fermented sausages [16] were observed in earlier studies, while lipase production in all isolates of $S$. aureus obtained from cow's milk was found in another study [17].

The idea that $S$. aureus isolates obtained from ricotta cheeses in this study are of human origin is provocative due to the high frequency of lipolytic activity observed among these isolates and the already reported ability to produce lipase in most of the $S$. aureus isolates obtained from humans $[13,14]$. Contamination of these samples (cheeses) may be related to improper handling, suggesting that meatand vegetable-contact surfaces are contaminated in a similar manner. Nevertheless, the high frequency of lipolytic activity among the isolates from foods and food-contact surfaces reveals the potential of these isolates to spoil foods, particularly through their action on lipids, which would result in decreased food quality and shelf life.

Although only a limited number of isolates of $S$. aureus from animals and food-contact surfaces were analyzed, the findings of this study show a clear difference in the frequency of lipase-producing isolates from different sources, which suggests that this feature could be related to the environment in which the isolate is harbored. The higher frequency of lipase-producing isolates in human wounds, foods, and food-contact surfaces demonstrates the need to control $S$. aureus in health care and food-processing environments because lipase production enhances pathogenicity and food-spoiling ability of this bacterium.

\section{References}

1. Popowicz GM, Dubin G, Stec-Niemczyk J, Czarny A, Dubin A, Potempa J, Holak TA (2006) Functional and structural characterization of $\mathrm{Spl}$ proteases from Staphylococcus aureus. J Mol Biol 358: 270-279.

2. Morell EA, Balkin DM (2010) Methicillin-resistant Staphylococcus aureus: a pervasive pathogen highlights the need for new antimicrobial development. Yale J Biol Med 83: 223-233.

3. Ifesan BOT, Hamtasin C, Mahabusarakam W, Voravuthikunchai SP (2009) Inhibitory effect of Eleutherine Americana err. extract on Staphylococcus aureus isolated from food. J Food Sci 74: 31-36.

4. Soares JC, Marques MR, Tavaria FK, Pereira JO, Malcata FX, Pintado MM (2011) Biodiversity and characterization of Staphylococcus species isolated from a small manufacturing dairy plant in Portugal. Int J Food Microbiol 146: 123-129.

5. Saxena S, Gomber C (2010) Superoxide dismutase, protease and lipase expression in clinical isolates of Staphylococcus aureus: a tool for antimicrobial drug discovery. Mol Cel Biochem 341: 217-223.

6. Smeltzer MS, Hart ME, Iandolo JJ (1992) Quantitative spectrophotometric assay for staphylococcal lipase. Appl Environ Microbiol 58: 2815-2819.

7. Xie W, Khosasih V, Suwanto A, Kim HK (2010) Characterization of lipases from Staphylococcus aureus and Staphylococcus epidermidis isolated from human facial sebaceous skin. J Microbiol Biotechnol 22: 84-91.

8. Gündğan N, Devren A (2010) Protease and lipase activity of Staphylococcus aureus obtained from meat, chicken and meatball samples. Gazi University Journal of Science 23: 381-384.

9. Downes FP, Ito K (2001) Compendium of methods for the microbiological examination of foods, 4th edition. Washington: American Public Health Association 676 p.

10. Pereira MSV, Siqueira-Júnior JP (1995) Antimicrobial drug resistance in Staphylococcus aureus isolated from cattle in Brazil. Let Appl Microbiol 20: 391-395.

11. Sierra G (1957) A simple method for the detection of lipolytic activity of microrganisms and some observations on the influence of the conctact between cells and fatty substrates. Antonie van Leeuwenhoek J Microbiol 23: 15-22.

12. $\mathrm{Hu} \mathrm{C}$, Xiong N, Zhang Y, Rayner S, Chen S (2012) Functional characterization of lipase in the pathogenesis of Staphylococcus aureus. Biochem Biophys Res Commun 419: 617-620.

13. Owens JJ, John PCL (1975) The egg yolk and lipolytic reaction of coagulase positive staphylococci. J Appl Bacteriol 39: $23-30$.

14. O'toole DK (1987) Differences in egg yolk reaction on BairdPacker medium between bovine and human strains of coagulase-positive staphylococci. Lett Appl Microbiol 4: 111112.

15. Araújo, MLC, Ito IY, Santiago MEB, Cardoso MS, Cunha EC (1986) Staphylococcus aureus: Pesquisa de portadores bovinos em lactação e antibiograma das cepas isoladas. Braz J Microbiol 17: 350-355.

16. Drosinos EH, Paramithiotis S, Kolovos G, Tsikouras I, Metaxopoulos I (2007) Phenotypic and technological diversity of lactic acid bacteria and staphylococci isolated from traditionally fermented sausages in Southern Greece. Food Microbiol 24: 260-270. 
17. Tebaldi VMR, Oliveira TLC, Boari CA, Piccoli BH (2008) Isolation of coliforms, staphylococci, and enterococci in raw milk from communitarian expansion refrigeration tanks: identification, lipolytic and proteolytic action. Food Sci Technol 28: 753-760.

\section{Corresponding author}

Evandro Leite de Souza

Universidade Federal da Paraíba

Centro de Ciências da Saúde, Departamento de Nutrição

Campus I, 58051-900, Cidade Universitária

João Pessoa, Paraíba, Brasil

Phone: + 558332167807

Fax: + 558332167094

Email: evandroleitesouza@ccs.ufpb.br

Conflict of interests: No conflict of interests is declared. 